\title{
A qualitative study exploring the relationship between nursing and health promotion language, theory and practice
}

\author{
Stewart Piper \\ HSHS \\ Anglia Ruskin University \\ Peterborough District Hospital \\ Thorpe Road \\ Peterborough \\ PE3 6DA \\ United Kingdom
}

\section{Keywords:}

\author{
Health education; \\ Health promotion; \\ Qualitative research; \\ Nurse education
}

\section{Summary}

The definitions and meaning qualified nurses employed in an acute NHS hospital setting in the UK gave to health education and health promotion practice and how these fitted established language and theory were investigated qualitatively. These concepts, and the concomitant frameworks and models of practice, have been the subject of considerable debate in the literature. While unresolved both in general and in nursing, a degree of theoretical convergence was established in the 1990s [Bunton, R., Macdonald, G., 1992. Health promotion: disciplines and diversity. Routledge, London; Maben, J.M., Macleod Clark, J. 1995. Health promotion: a concept analysis. Journal of Advanced Nursing 22, 1158-165] helped by The Ottawa Charter [WHO, 1986. Ottawa Charter for Health Promotion. http:// www.who.int/hpr/archive/docs/ottawa.html]. For many of the participants in this study however, the meanings given to these concepts and the predominant use of health education were inconsistent with much of the language of the wider debate and this has potential implications for nurse education. For, if the findings are considered transferable then there is a need to develop education strategies and curricula that articulate the ideological foundations of policy and practice and to use mainstream terminology to assist nurses both to understand and contribute to the contemporary health promotion debate.

\section{Background}

Developments in UK health policy (DoH, 1992, 1998, 1999a, 2000), strategies for nursing (DoH, 1989, 1993, 1999b) and The Nursing and Midwifery Council (2004a,b, 2005) have emphasised increasingly the health promotion aspect of practice. In addition, competence in illness prevention and health promotion is a feature of UK Nurse Training Rule 18 (1) and the inception of Project 2000 nurse training shifted the curriculum emphasis from a disease to a health model. However, health education and health promotion are contested concepts. In 1964, The Ministry of Health struggled with the meaning of the former and this set the tone for subsequent discussion. Traditional definitions of health education include improving knowledge and understanding for changes in health-related behaviour (Baric, 1982, 1985; Nutbeam, 1986; Tones, 1990; Bunton and Macdonald, 1992; Tones and Tilford, 2001) and helping people access health services and manage problems before using them (Baric, 1982, 1985). For some, it came to embrace more radical notions of empowerment (Greenberg, 1978; Tones, 1981, 1986; Tones and Tilford, 1994, 2001; Naidoo and Wills, 2000) and community needs/development (Griffiths, 1972; WHO, 1983; Tannahill, 1985).

In defining health promotion, The Ottawa Charter (WHO, 1986) widened the debate by emphasising a population approach, a focus on social policy, community development, public participation and partnership working between organisations as well as combining personal choice with social responsibility. It was significant because it represented a departure from the medical model to a socio-political position advocating the shift of power from 
bureaucracies to people (Green and Raeburn, 1988). It thus widened and redefined the concept of healthy public policy (Jones, 1997).

The nursing literature found confusion and inconsistency over the meaning of health promotion (Latter et al., 1992; Macleod Clark et al., 1991; Delaney, 1994; King, 1994; Maben and Macleod Clark, 1995; Norton, 1998; Whitehead, 2006) and a lack of a distinctive nursing focus (Berg and Sarvima"ki, 2003). Morgan and Marsh (1998) noted the narrow definition of health promotion emphasising individual risk factors, lifestyle and responsibility. Macleod Clark et al. (1996) found that health promotion was described in terms of contemporary definitions of health education and Brubaker (1983) revealed a failure to differentiate between health promotion, disease prevention, health maintenance, community health and wellness. Anderson (1984), Latter et al. (1992), King (1994) and Whitehead (2004) also noted the interchangeable use of language while for Lask (1987) health education included social and environmental elements and, for Latter et al. (1992), raising public awareness about these issues.

The debate was accompanied by the generation of competing frameworks and models of health education/promotion culminating in the UK in an edition of the Health Education Journal (1990) devoted to this conceptual wrangling. Nevertheless, agreement over a unifying framework or model for conceptualising theory and practice in general remains elusive (Naidoo and Wills, 2000; Tones and Tilford, 2001). Despite the frameworks and models developed or synthesised by Coutts and Hardy (1985), Davis (1995), Kiger (1995), Pender (1996), Kuss et al. (1997), Piper and Brown (1998), Piper (2000), Whitehead (2001) and Gonser and McGuinness (2001) this is also the position in nursing.

A limited number of studies have been also conducted on health education/promotion in hospital settings. Macleod Clark et al. (1991) and Latter et al. (1992) reported that health education practice was limited to the categories of patient education, information giving and healthy lifestyle advice rather than on encouraging patient and family participation in care. Wilson-Barnett and Latter (1993) also found that the more contemporary and broader aspects of health education such as collaboration, participation and empowerment were not included. This is consistent with the findings of Gott and O'Brien (1990), Maidwell (1996) and Twinn and Lee (1997) in reflecting a medical and didactic model of nurse/patient interaction with Twinn and Lee (1997) advancing that nurses limited their definition of health education to patient information. Maidwell's (1996) findings on nurses working in surgical settings were consistent with those of McBride (1994) in establishing that health promotion was not only part of the role, but also an essential element that goes hand in hand with nursing care. In defining health promotion, the nurses in the study emphasised disease prevention and management, but also indicated a move toward encouraging patient participation in care, education and healthy lifestyle advice.

In relation to project 2000 educated nurses in the UK, Macleod Clark et al. (1996) found that while participants differentiated between health education and health promotion, there was some confusion over their defining characteristics. The findings echo the biomedical emphasis of philosophy of health and health promotion in the educational curriculum and its integration in four nurse education institutions in England (Smith et al., 1995a,b). Conversely, McDonald (1998) found that perceptions of health promotion included, but also went beyond, traditional information giving and patient teaching to supporting and encouraging patients in their decision making, negotiating and collaborating over needs and involving patients and their significant others in care management, advocacy and empowerment. Similarly Hills (1998) cites the primacy given to patients as people and the nurse-patient relationship/partnership, a person-centred approach, empowerment and an awareness of the social context of the patient's life. Mitchenson (1995) similarly compared the attitudes and beliefs of Project 2000 student nurses with those educated in a traditional way, while Ward (1997) explored student nurses' perceptions of the role of the nurse as a health promoter.

Mitchenson found that health promotion was seen as an important part of practice and enthusiasm for the role. It involved modifying unhealthy behaviour with the nurse as dominant in the process. Examples of where there were disagreements included more emphasis given to psychosocial wellbeing, less tolerance of circumstances impeding health promotion, but 
paradoxically also a greater tendency to coercion by Project 2000 students. Another difference was that traditionally trained nurses felt that there was insufficient time to practice health promotion. For Ward (1997), health promotion was predominantly seen as information giving and lifestyle and risk factor advice rather than about more empowering type strategies and the responses of the students indicated an adherence to hospital routines.

\section{Methods}

The aim of the study was to explore the definition and meaning hospital nurses gave to health education and health promotion and consider how these fit with existing language and theory. Qualitative data were collected by individual and focus group interviews and the Critical Incident Technique (CIT) (Flanagan, 1954). The focus group interviews particularly suited the theoretical focus of the study in facilitating the exploration and clarification of the language and meaning of health education/promotion through dialogue and the sharing of perceptions and reactions to the contribution of others (Stewart and Shamdasani, 1990; Carey, 1994; Kitzinger, 1995). It is, however, acknowledged that as a result only relatively shallow data were collected at the expense of the depth of understanding that can be gleaned from the individual interview method. All were partially structured using an interview guide outlining the 'broad concepts' (Carey, 1994, p. 228) to be explored to ensure consistency and a systematic approach (Patton, 1990; May, 1991; Holloway and Wheeler, 1996) while allowing considerable latitude for the participants' answers (Streubert and Carpenter, 1999). The interview guide derives from the framework of quality indicators of The Society of Health Education and Health Promotion Specialists (Totten, 1992). The framework was constructed for measuring and monitoring the process and outcomes of health promotion and to help clarify the operational targets of intervention at different stages of the process.

The CIT is a systematic, open-ended, verbal or written process (Norman et al., 1992) that can be used to develop theory in exploratory interpretive research (Woolsey, 1986). Flanagan (1954) emphasised that the CIT is a flexible method for observing human behaviour that should be modified and adapted as required and not a rigid set of rules for data collection. This is supported by Twelker (2003), who contends that the CIT is particularly suited to identifying gaps in knowledge and understanding. Here, eight deviant/paradigm case participants were asked to develop a significant incident from their nursing practice that they had referred to in an earlier interview with the purpose of gaining a deeper insight into the participants' definitions of health education/promotion and aims, methods and outcomes of practice. Data were collected from retrospective accounts using the qualitative questionnaire of Benner (1984) who developed the technique for her research into levels of expertise in nursing and by interview (Woolsey, 1986; Norman et al., 1992).

All thirty-two participants worked in an acute hospital and were purposively sampled from across the clinical and management grading structure and from acute and emergency care, older people, oncology and sexual health settings. The intention was to create the possibility of generating a range of analytical variables and to test their degree of fit with existing definitions and theory rather than to reach a shared understanding.

The audiotaped individual and focus group interviews were transcribed, coded and analysed both by using the manual guidelines of Hycner (1985) and computer-assisted qualitative data software (QSR NUD*IST Vivo) to facilitate analysis triangulation. Use of Hycner's (1985) guidelines involved listening to the interviews to get a sense of the whole, delineating units of general and relevant meaning, eliminating redundancies, clustering units of relevant meaning and identifying and contextualising themes from the latter. To help the reader engage with and further contextualise the findings, while ensuring confidentiality, participants were given fictitious names with minimal but real professional biographical details. The fieldwork was conducted according to the University Ethics Guidelines for Research for use when undertaking research with human subjects and was approved by the appropriate Research Degree Committee. 


\section{Results}

The role of the nurse as Informer was the central theme of the findings and of health education practice and involved the dissemination of information to the patient to increase knowledge and understanding of disease, diagnosis, prognosis and treatment and assist with decision making. It underpinned the two sub-themes of Behaviour Change and Empowerment. The former aimed to achieve behavioural outcomes defined by the nurse and thus therapeutic compliance and self-management in line with these by patients. This was achieved through informing, patient teaching and awareness raising within the context of secondary prevention and was based on the assumption that patients were free to choose their health/disease- related behaviour and lifestyle. Empowerment included helping patients understand their predicament, think positively, psychological support, rapport building, developing a nurse/patient partnership, configuring services around the aspirations and convenience of the patient and promoting participation in service user groups and advocacy. It also involved helping people be aware of what treatment options were available and exercise informed choice, have some control in relation to their illness and come to terms and cope with the constraints and disabilities it imposed.

The most surprising findings were the deviant/paradigm cases that described atypical interventions. The title of Strategic Practice was advanced by Tracey when discussing working at a multidisciplinary and multiagency level and with industry for organisational, policy and operational change. It included health surveillance, liaison with the other agencies, admission avoidance and thus strategic practice at an internal operational level. Advocacy was not about advocating for patients individual needs, helping them with decision making, fighting on their behalf for the therapeutic interventions they wanted or resisting the pressure of health care professionals for a particular course of action. It was about collective empowerment where the nurse raised the profile, lobbied and advocated on behalf of a disempowered hospital patient population and championed their needs as they lacked a strong group voice and experienced marginalisation.

Greater depth and a more formal approach then, underpinned by a medical knowledge base was attributed to health education. The focus was the unique and specific health needs of individual patients in the context of disease or injury, hospital setting and client group, for example:

Judith: (general nurse) "...health education has a more formalised approach to it, perhaps more of a sort of sit down with them teaching session or a booklet, whereas health promotion is a more of an informal ongoing thing that goes on a lot outside of a hospital set-up."

Adrian: (Senior Clinical Nurse, Emergency Care) "health education is for your specific area... a bit more about saying to someone...this is an issue that you need to consider...you've had a fall, you've got a chest injury, you smoke therefore you are more at risk of a chest infection ..."

Debbie: (oncology nurse) "Health Education...is educating the patients in relation to their condition and their health..."

Sarah: (oncology nurse) "...in terms [of] education of my patients there is a lot you can do as a nurse. You can break down some of the barriers, break down some of the information so that they understand exactly what cancer is...how the body has changed in such a way that this cancer has occurred and then where they go from here, how they treat it."

Tracey: (Service manager) "...there are things that we need to say in order to help them to move from where they are now to back to where they were before, some very specific things that they need to do and I guess those are the educative things." 
For some health promotion was less formal, topic specific interventions that could be an opportunistic part of hospital nursing practice and, most importantly in terms of a distinguishing feature, unrelated to the patients presenting condition. Unlike health education, health promotion did not focus on individual patient needs, did not involve teaching about disease or presenting problems and was more concerned with primary prevention. It included giving general advice on health matters, helping people manage negative things in their life and helping them move from being unhealthy to a state of wellbeing. While not absent from the life of hospital nurses, it was seen as more of a community-based activity. It took the form of wider scale targeted primary prevention interventions for the entire population that use the mass media and health professionals to provide guidance on the 'do's and don'ts, the rights and wrongs' (Frances, Senior Clinical Nurse, Sexual health) and 'government propaganda' on health matters such as 'cigarette smoking' and 'drinking and driving' (Adrian) for example:

Monica: (Senior Clinical Nurse, Emergency Care) "...health promotion is a wider scale of targeting promotion or larger sort of ideas like preventing accidents and cancer."

Edith: (Lecturer/Practitioner, Medicine for the Elderly) "I also think about big things as well with health promotion, like um, giving up smoking and you know the things that are really government ideas about how we should live..."

Wendy: (Executive Nurse) "...my children at the moment see the School Nurse so they're encouraged to be active in the school, they're encouraged to eat good food, not watch television all the time, do lots of exercise, well that's health promotion because its trying to prevent something from happening."

Sarah: "health promotion is almost all the way across the media and there is many ladies in society who have not gone untouched by much of the health promotion that's gone on in breast cancer care recently."

Tracey: "the promotion things are perhaps added onto that in terms of maybe icing on the cake really, you know, the extra things that they might want to do but are not necessarily bound up with what they've got but generally will promote a healthier living. I guess promotion is about this is an opportunity for you to be able to take this on board if you want to, education perhaps is much more restricted in the sense that you really need it to happen in order for it to make a difference."

Sheila: (Senior Clinical Nurse, Emergency Care) "I see health promotion as a broader concept...I see education as specific to people that we contact, without anything like smoking, to do with your injury. I see that as education, but promotion I see as campaigns and policies and procedures and legislation and all that leading to those things."

One participant expressed the view that a variety of people could be health promoters but health education was the domain of health care professionals.

\section{Discussion}

The one-to-one interpersonal focus of Behaviour Change and Empowerment are concerned with the health-related knowledge, attitudes and lifestyle of individuals based on the assumption that these are key determinants of health status. However, in operating from different positions on the power continuum, they invoke different aims, methods and outcomes and thus different indicators of success in terms of health gain. Behaviour Change was top-down, 'expert directed', the participants maintained a 'high social distance' (Beattie, 1991, p. 185) and derived their power base from biomedical research highlighting the relationship between disease, risk factors and lifestyle and control of the latter and the risks to individuals if they fail to pursue the prescribed course of action was emphasised.

It is unsurprising that Empowerment was a theme of the findings as it reflects the language of much of the contemporary health and social care discourse and developing consumer, 
advocacy (DoH, 2002) and 'expert patient' (DoH, 2001) culture in the NHS in the UK. The focus was more on patient control and choice, a 'bottom-up' model of intervention and a lower 'social distance' (Beattie, 1991, p. 185) and included the role of practitioner as 'advocate' (Beattie, 1991, p. 187) and helping patients adapt positively to changes in health status. Nevertheless, this was still in relation to disease management and associated boundaries and where choice was facilitated this was within the available resources and options. As such, it represented empowerment as a technology (Tones, 2001) i.e., a technical, skill-based process involving face-to-face encounters concerned with simple pragmatic day-to-day supportive and enabling strategies. Any change in the dynamic of the nurse/patient relationship was a modification of enduring and traditional roles

The deviant/paradigm cases of Strategic Practice and Advocacy enable practice to be conceptualised from a macro and micro population focus. The former is concerned with operational issues at a hospital and departmental level and reflect strategic, organisational and policy interventions, professionally assessed needs and associated aims, methods and outcomes of practice. They are 'managerialist' and 'professionalist' and maintain a hierarchy and a system of subordination with the practitioner maintaining a 'high social distance' (Beattie, 1991, p. 187). Advocacy focuses on intervention with a patient population on an institutional scale and interventions that are client-centred and concerned with a form of micro population empowerment.

\section{Implications for nurse education}

For the most part, the narrow meaning given to health promotion by the participants relates to limited forms of intervention and not activities associated with the Ottawa Charter (WHO, 1986), the mainstream literature or modern public health (e.g. DoH, 1999a,b, 2003). Whitehead $(2003,2006)$ echoes this concern in noting that nurses are failing to conceptualize the difference between health education and health promotion and contemporary meanings in favour of traditional perspectives. The contention here is that if this position persists, and if nurse educators consider the findings of this study transferable and that mainstream language is not being used, then the nursing voice may not be heard by other disciplines (Gottlieb, 1992) and may become 'invisible' (Falk Rafael, 1999, cited in Whitehead, 2006). This may result in nursing failing to make a full contribution to the health promotion theory and practice debate. The re-orientation of UK health policy over the last decade emphasising health promotion as a health service priority and placing it explicitly on the nursing agenda (for example, DoH, 1992, 1993, 1999a,b, 2000) makes this more significant than ever. This may also be compounded by the introduction of competing contemporary terminology such as 'health development' and the recent introduction of the term 'public health' in relation to practitioners working in the community and the partnership working between agencies agenda.

Thus, while impossible to advance a final, absolute definition of health promotion (Whitehead, 2004), nurse educators need to define health promotion for nursing (Berg and Sarvima"ki, 2003) and nursing practice (Robinson and Hill, 1998) while using the language of policy makers and other disciplines to facilitate both understanding and a contribution to the wider health promotion debate. Drawing attention to, and making explicit the contemporary terminology and its meaning also has to be a feature of the nursing curriculum and associated teaching and learning strategies for the twenty-first century. This should be accompanied by a clear outline of the strengths, weaknesses, aims, methods and outcomes of the various models of health education/health promotion intervention to contextualise the terminology and related practice. This would fall in line with Whitehead's (2003) call for nurses to adopt a structured and systematic approach to health promotion. This can be partially achieved by Burke and Smith's (2000) audit tool but if nursing wants to make a full contribution to health promotion the philosophy and organisational structures underpinning practice (Robinson and Hill, 1998; Northrup and Purkis, 2001) and concomitant curricula (Rush, 1997) must also be clearly articulated.

In terms of implications for patients/clients, it is important to remember that focusing on Behaviour Change and the 'visible' (Rush, 1997) aspects of health promotion remains important and may be assisted by utilising different teaching strategies to facilitate learning 
(Hsiao et al., 2005). However, the socio-political factors such as inequalities (the 'invisible') must also be addressed (Morgan and Marsh, 1998; Robinson and Hill, 1998; Burke and Smith, 2000). Hence, Whitehead $(2004,2006)$ contends that socio-political processes in the form of community development approaches to health promotion have superceded individualistic forms and nursing [and thus nurse education] should attempt to reflect this wider agenda. Such endeavour may also require alternative models of teaching (FalkRafael et al., 2004).

\section{Conclusion}

The aim of the research was to discover and understand the meaning nurses gave to health education and health promotion and to establish how these fitted with existing language, theory and practice. For many participants, health education was more formal, had broader meaning, processes and outcomes and had a greater depth than health promotion. It was concerned with the unique and specific needs of individual patients and health/diseaserelated behaviour change, and facilitating various empowerment interventions. In the main, health promotion was viewed as a less formal, mass media and campaigning approach that also used health professionals, mostly based in primary care, for prevention and general health advice but any socio-political role was overlooked. This is inconsistent with contemporary conceptualisation and if nurse educators judge that the findings from this qualitative study accord with their experience are trustworthy and are thus transferable into their world then nursing may be disadvantaged when trying to contribute to an important debate and this must be addressed.

\section{References}

Anderson, R., 1984. Health promotion: an overview. In: Baric, L.(Ed.), European Monographs in Health Education research. Scottish Health Education group.

Baric, L., 1982. A new ecological perspective emerging for health education. The Journal of the Institute of Health Education 20 (4), 5-21.

Baric, L., 1985. The meaning of words: health promotion. The Journal of the Institute of Health Education 23 (1), 10-16.

Beattie, A., 1991. Knowledge and control in health promotion: a test case for social policy. In: Gabe, J., Calnan, M., Bury, M. (Eds.), The Sociology of the Health Service. Routledge, London, pp. 162-202.

Benner, P., 1984. From Novice to Expert: Excellence and Power in Clinical Nursing Practice. Addison-Wesley, California.

Berg, G.V., Sarvima"ki, A., 2003. A holistic-existential approach to health promotion. Scandinavian Journal Caring Sciences 17, 384-391.

Brubaker, B.H., 1983. Health promotion: a linguistic analysis. Advances in Nursing Science 5, $1-14$.

Bunton, R., Macdonald, G., 1992. Health Promotion: Disciplines and Diversity. Routledge, London.

Burke, L.M., Smith, P., 2000. Developing an audit tool for health promotion learning opportunities in clinical placements. Nurse Education Today 20, 475-484.

Carey, M.A., 1994. The group effect in focus groups: planning, implementing, and interpreting focus group research. In: Morse, J. (Ed.), Critical Issues in Qualitative Research Methods. Sage, Thousand Oaks.

Coutts, L.C., Hardy, L.K., 1985. Teaching for Health: the Nurse as Health Educator. Churchill Livingstone, Edinburgh.

Davis, S.M., 1995. An investigation into nurses' understanding of health education and health promotion within a neuro-rehabilitation setting. Journal of Advanced Nursing 21, 951959.

Delaney, F.G., 1994. Nursing and health promotion: conceptual concerns. Journal of Advanced Nursing 20, 828-835.

Department of Health, 1989. A Strategy for Nursing. Department of Health Nursing Division, London.

Department of Health, 1992. The Health of the Nation: A strategy for health in England. HMSO, London. 
Department of Health, 1993. Targeting Practice: The contribution of Nurses, Midwives and Health Visitors. The Health of the Nation. HMSO, London.

Department of Health, 1998. Smoking Kills: A White Paper on Tobacco. The Stationary Office, London.

Department of Health, 1999a. Saving Lives: Our Healthier Nation. HMSO, London.

Department of Health, 1999b. Making a Difference: Strengthening the Nursing, Midwifery and Health Visiting Contribution to Health and Healthcare. HMSO, London.

Department of Health, 2000. The NHS Plan: A Plan for Investment, a Plan for Reform. HMSO, London.

Department of Health, 2003. Liberating the Talents: Helping Primary Care Trusts and nurses Deliver the NHS Plan. HMSO, London.

Falk-Rafael, A.R., Ward-Griffin, C., Laforet-Fliesser, Y., Beynon, C., 2004. Teaching nursing students to promote the health of communities: a partnership approach. Nurse Educator 29 (2),63-67.

Flanagan, J., 1954. The critical incident technique. Psychological Bulletin 51 (4), 327-358.

Gonser, P., McGuinness, T.M., 2001. Theoretical underpinnings of health promotion in acute care. Nurse Practitioner Forum. 12 (3), 147-150.

Gott, M., O'Brien, M., 1990. Attitudes and beliefs in health promotion. Nursing Standard 5 (2), 30-32.

Gottlieb, L., 1992. Nurses are not heard in the health promotion movement. Canadian Journal of Nursing research 24 (4), 1-2.

Green, L.W., Raeburn, J.M., 1988. Health promotion. What is it? What will it become? Health Promotion 3 (2), 151-159.

Greenberg, 1978. Health education as freeing. Health Education (March/April), 20-21.

Griffiths, W., 1972. Health education: philosophy, goals, methods, needs and consequences. Health Education Monographs 31, 7-11.

Health Education Journal, 1990. 49 (1).

Hills, M., 1998. Student experiences of nursing health promotion practice in hospital settings. Nursing Inquiry 5, 164-173.

Holloway, I., Wheeler, S., 1996. Qualitative Research for Nurses. Blackwell, Oxford.

Hsiao, Y., Chen, M., Gau, Y., Hung, L., Chang, S., Tsai, H., 2005. Short-term effects of a health promotion course for Taiwanese nursing students. Public Health Nursing 22 (1), 74-81.

Hycner, R.H., 1985. Some guidelines for phenomenological analysis of interview data. Human Studies 8, 279-303.

Jones, L., 1997. Health promotion and public policy. In: Jones, L., Sidell, M. (Eds.), The Challenge of Promoting Health: Exploration and Action. Macmillan/Open University, Hampshire, pp. 91-111.

Kiger, A.M., 1995. Teaching for Health, second ed. Churchill Livingstone, Edinburgh.

King, P.M., 1994. Health promotion: the emerging frontier in nursing. Journal of Advanced Nursing 20, 209-218.

Kitzinger, J., 1995. Introducing focus groups. British Medical Journal 311, 299-302.

Kuss, T., Proulx-Giroud, L., Lovitt, S., Katz, C.B., Kennelly, P., 1997. A public health nursing model. Public Health Nursing 14 (2), 81-91.

Lask, 1987. Beliefs and behaviour in health education. Nursing 18, 681-683.

Latter, S., Macleod Clark, J., Wilson-Barnett, J., Maben, J., 1992. Health education in nursing: perceptions of practice in acute settings. Journal of Advanced Nursing 17, 164-172.

Maben, J.M., Macleod Clark, M., 1995. Health promotion: a concept analysis. Journal of Advanced Nursing 22, 1158-1165.

Macleod Clark, J., Wilson-Barnett, J., Latter, S., 1991. Health Education in Nursing Project: Results of a National Survey on Service Nurse Perceptions of Health Education Practice in Acute Ward Settings. King's College, London.

Macleod Clark, J., Maben, J., Jones, K. 1996. Project 2000: perceptions of the philosophy and practice of nursing.http://www.enb.org.uk/rh17.htm.

Maidwell, A., 1996. The role of the surgical nurse as a health promoter. British Journal of Nursing 5 (15), 898-904.

May, K.A., 1991. Interview techniques in qualitative research: concerns and challenges. In: Morse, J.M. (Ed.), Qualitative Nursing Research: A Contemporary Dialogue. Sage, London, pp. 188-201. 
McBride, A., 1994. Health promotion in hospitals: the attitudes, beliefs and practices of hospital nurses. Journal of Advanced Nursing 20, 92-100.

McDonald, E., 1998. The role of Project 2000 educated nurses in health promotion within the hospital setting. Nurse Education Today 18, 213-220.

Ministry OF Health, 1964. Health Education. Report of a joint committee of the Central and Scottish Health Services Councils. HMSO, London.

Mitchenson, S., 1995. A review of health promotion and health beliefs of traditional and Project 2000 student nurses. Journal of Advanced Nursing 21, 356-363.

Morgan, I.S., Marsh, G.W., 1998. Historic and future health promotion contexts for Nursing. Journal of Nursing Scholarship 30 (4), 379-383.

Naidoo, J., Wills, J., 2000. Health Promotion: Foundations for Practice, second ed. Baillie're Tindall, London.

Norman, I.J., Redfern, S.J., Tomalin, D.A., Oliver, S., 1992. Developing Flanagan's critical incident technique to elicit indicators of high quality and low quality nursing care from patients and nurses. Journal of Advanced Nursing 17, 590-600.

Northrup, D.T., Purkis, M.E., 2001. Building the science of health promotion practice from a human science perspective. Nursing Philosophy 2, 62-71.

Norton, L., 1998. Health promotion and health education: what role should the nurse adopt in practice?. Journal of Advanced Nursing 28 (6) 1269-1275.

Nursing and Midwifery Council, 2004a. Standards of proficiency for pre-registration nursing education, www.nmc-uk.org.

Nursing and Midwifery Council, 2004b. Standards of proficiency for specialist community public health nurses, www.nmcuk.org.

Nursing and Midwifery Council, 2005. Consultation on a framework for the standard for postregistration nursing,www.nmc-uk.org.

Nutbeam, D., 1986. Health promotion glossary. Health Promotion 1 (1), 113-126.

Patton, M.L., 1990. Qualitative Evaluation and Research Methods. Sage, London.

Pender, N.J., 1996. Health Promotion in Nursing Practice, third ed. Appleton and Lange, Stamford.

Piper, S.M., 2000. Promoting Health. Nursing Management 7 (4),8-11.

Piper, S.M., Brown, P.A., 1998. The theory and practice of health education applied to nursing: a bi-polar approach. Journal of Advanced Nursing 27, 383-389.

Robinson, S., Hill, Y., 1998. The health promoting nurse. Journal of Clinical Nursing 7, $232-$ 238.

Rush, K.L., 1997. Health promotion ideology and nursing education. Journal of Advanced Nursing 25, 1292-1298.

Smith, P., Masterson, A., Lask, S., 1995a. Health and the curriculum: an illuminative evaluation - Part 1: Methodology. Nurse Education Today 15, 245-249.

Smith, P., Masterson, A., Lask, S., 1995b. Health and the curriculum: an illuminative evaluation - Part 2: Methodology. Nurse Education Today 15, 317-322.

Stewart, D.W., Shamdasani, P.N., 1990. Focus Groups: Theory and Practice. Sage, Newbury Park.

Streubert, H.J., Carpenter, D.R., 1999. Qualitative Research in Nursing: Advancing the Humanistic Imperative. Lippincott,Philadelphia.

Tannahill, A., 1985. What is health promotion?. Health Education Journal 44 (4) 167-168.

Tones, B.K., 1981. Health education: prevention or subversion? Royal Society of Health Journal 3, 114-117.

Tones, B.K., 1986. Health education and the ideology of health promotion: a review of alternative approaches. Health Education Research 1 (1), 3-12.

Tones, K., 1990. Why theorise? Ideology in health education. Health Education Journal 49 (1), 2-6.

Tones, K., 2001. Health promotion: the empowerment imperative. In: Scriven, A., Orme, J. (Eds.), Health Promotion: Professional Perspectives. Palgrave, Basingstoke, pp. 318.

Tones, K., Tilford, S., 1994. Health Education: Effectiveness, Efficiency and Equity, second ed. Chapman \& Hall,London.

Tones, K., Tilford, S., 2001. Health Promotion: Effectiveness, Efficiency and Equity, third ed. Nelson Thornes, London. 
Totten, C. (Ed.), 1992. Developing quality in health education and health promotion: a manual for all those involved in the delivery of a quality service. The Society of Health Education and Health Promotion Specialists.

Twelker, P.A.2003. The critical Incident technique: A manual for its planning and implementation. http://www.tiu.edu/psychology/Twelker/critical_incident_technique.htm.

Twinn, S.F., Lee, D.T.F., 1997. The practice of health education in acute care settings in Hong Kong: an exploratory study of the contribution of registered nurses. Journal of Advanced Nursing 25, 178-185.

Ward, M., 1997. Student nurses' perceptions of health promotion: a study. Nursing Standard 11 (24), 34-40.

Whitehead, D., 2001. A stage planning programme model for health education/health promotion practice. Journal of Advanced Nursing 36 (2), 311-320.

Whitehead, D., 2003. Evaluating health promotion: a model for nursing practice. Journal of Advanced Nursing 41 (5), 490-498.

Whitehead, D., 2004. Health promotion and health education: advancing the concepts. Journal of Advanced Nursing 47 (3),311-320.

Whitehead, D., 2006. Commentary on Irvine F (2005) Exploring district nursing competencies in health promotion: the use of the Delphi technique. Journal of Clinical Nursing 14, 965-975.

WHO, 1983. New approaches to health education in primary care. Report of a WHO Expert Committee. WHO Technical Report Series 690.

WHO, 1986. Ottawa Charter for Health Promotion. http://www. who.int/hpr/archive/docs/ottawa.html.

Wilson-Barnett, J., Latter, S., 1993. Factors influencing nurses' health education and health promotion practice in acute ward areas. In: Wilson-Barnett, J., Macleod Clark, J. (Eds.), Research in health promotion and nursing. Macmillan, Basingstoke, pp. 6171.

Woolsey, L.K., 1986. The critical incident technique: an innovative qualitative method of research. Canadian Journal of Counselling 20 (4), 242-254. 